\title{
Jovem Aprendiz: a inclusão social na regiáo Vale do Paranhana
}

Camila Engelmann ${ }^{1}$ - Dilani Silveira Bassan²

\section{Resumo}

Este trabalho tem como objetivo verificar se a empresa pesquisada utiliza o projeto Jovem Aprendiz apenas para cumprir a legislação vigente, ou se está realmente preocupada com a inclusão e responsabilidade social. Para tal, foi realizada uma pesquisa qualitativa com entrevistas abertas para que fosse possível avaliar a viabilidade do projeto, suas deficiências e resultados alcançados. Por meio do resultado da pesquisa, foi possível constatar que a maior dificuldade encontra-se na legislação, que não condiz com a realidade atual, pois jovens de quatorze anos são impedidos por lei de trabalhar em locais que apresentam risco à sua integridade física, mesmo praticando essa atividade na forma de aprendiz. A pesquisa também apontou a necessidade de intensificar junto aos jovens uma mudança de visão no que se refere à qualificação profissional, a qual deve ser fortemente trabalhada a fim de viabilizar a construção de uma imagem positiva. Além disso, é por meio da qualificação que se adquire sucesso profissional e, consequentemente, há possibilidade de melhores índices de crescimento social, os quais contribuem para o desenvolvimento da região.

Palavras-chave: Jovem Aprendiz. Responsabilidade social. Desenvolvimento regional.

\section{Abstract}

This study aims to determine whether the company uses the project researched Young Apprentice, just to comply with existing legislation, or is really concerned with social inclusion and responsibility. To this end, a survey was conducted qualitative interviews with open so we could assess the feasibility of the project, its achievements and shortcomings. Through the search result it was found that the greatest difficulty lies in legislation that is inconsistent with the current reality, as young fourteen years are prevented by law from working in places that present a risk to their physical integrity

${ }^{1}$ Administradora de empresas. camila.engel@hotmail.com.

${ }^{2}$ Professora das Faculdades Integradas de Taquara - Faccat - Taquara (RS). Mestre em Desenvolvimento Regional. dilanib@faccat.br 
even practicing this Seen as an apprentice. The survey also identified a need to increase among young people a change of view with regard to professional qualification, this must be heavily worked in order to enable the construction of a positive image. Moreover, it is through training that is acquired professional success and therefore no possibility of better growth rates that consequently contribute to social development in the region.

Keywords: Young Apprentice. Social Responsibility. Regional Development.

\section{Introdução}

Este trabalho tem como tema central o programa de inclusão Jovem Aprendiz e visa verificar seu reflexo nas empresas e os benefícios que ele traz para as organizações, para a sociedade, para a região e para o jovem que dele participa. Além disso, a pesquisa busca a resposta para o seguinte questionamento: As organizações utilizam esses projetos apenas para cumprir a legislação vigente ou realmente estão preocupadas com a inclusão e a responsabilidade social?

A inclusão social e a formação do capital humano são grandes desafios do mundo atual. Projetos de inclusão como o Jovem Aprendiz possibilitam um elo entre a empresa e o jovem. Portanto, este trabalho pretende verificar se o programa de inclusão Jovem Aprendiz abrange as faixas sociais que necessitam desse recurso. Além disso, objetiva analisar de que forma as instituições de ensino e as empresas veem esse programa, procurando enfocar, especificamente, como as entidades são fiscalizadas, qual é o grau de importância que é dado para a qualificação e se são observadas melhorias no comportamento dos jovens, após serem inseridos no programa de aprendizado.

A pesquisa busca, por meio da teoria e da prática, verificar se as políticas públicas de inclusão social, em especial o projeto Jovem Aprendiz, são importantes como qualificação do capital humano, e se esse projeto de inclusão faz ou não parte da responsabilidade social das empresas.

De outra forma, e não menos importante, procura-se entender como a ética empresarial é tratada pelos gestores e de que maneira as organizações apoiam os projetos de inclusão. Também se objetiva verificar a eficácia da fiscalização, para que não haja apenas o "assistencialismo", mas uma cultura de cidadania e políticas públicas eficazes no que diz respeito à inclusão social.

Em relação ao aspecto social, seria essencial a constatação de que as organizações optam por programas dessa espécie não apenas para cumprir a lei, mas também porque se preocupam com a realidade da sociedade onde vivem, com o bem-estar de seus colaboradores e com a possibilidade de um futuro com opções para esses jovens, pois sabem da importância que a responsabilidade social exerce sobre a região na qual estão inseridas.

A pesquisa foi realizada em uma empresa do Vale do Paranhana, pois o processo de inclusão social dos jovens é um aspecto importante para o desenvolvimento regional. Os dados fornecidos e relatados por meio de entrevistas foram coletados nos três segmen- 
tos fundamentais para esse trabalho, a saber: Indústria - ramo calçadista, situada no Vale do Paranhana, atualmente com 2.800 funcionários; Senai - agência Igrejinha/RS, que atualmente dispõe de 35 vagas para capacitação de jovens; Ministério do Trabalho e Emprego (MTE) - agência Porto Alegre, cujas informações foram cedidas pela superintendente responsável pela aplicação e pela fiscalização do programa no Estado do Rio Grande do Sul.

Em tese, as empresas desenvolvem a possibilidade de ser o agente responsável pelo desenvolvimento da região que as absorve, através da inclusão dos jovens no mercado de trabalho, sem abandonar a qualificação.

A busca de respostas para todos esses questionamentos possibilita a análise e a compreensão de projetos, como o Jovem Aprendiz, o qual pode promover mudanças sociais, ou seja, a atuação da empresa cidadã, bem como as políticas públicas regionais, em um contexto de resultados de ações e seus reflexos para a comunidade local contribuindo positivamente para o desenvolvimento regional.

\section{Programa Jovem Aprendiz}

O Manual do Jovem Aprendiz (SILVA et al., 2009) foi desenvolvido pelo Governo Federal juntamente com o MTE, com base na Lei no 5.598 de dezembro/2005, para

promover a capacitação e a inclusão de jovens nos ambientes empresariais. É por meio desse manual que se tem acesso às informações básicas do Programa Jovem Aprendiz.

Esse programa engloba atividades teóricas e práticas com a mesma importância e carga horária. Os cursos devem estar relacionados diretamente com a atividade profissional, portanto a frequência às aulas interfere no resultado do programa, tanto que se o menor apresentar baixo desempenho e, por consequência, vir a repetir o ano, é automaticamente desligado do programa.

O projeto atende jovens de 14 a 24 anos que ainda não concluíram o ensino médio, pois se sabe que muitos começam a trabalhar cedo e tendem a abandonar os estudos, tendo assim, geralmente, pouca perspectiva de crescimento dentro das empresas.

As organizações que tenham, no mínimo, sete funcionários, são obrigadas a implantar o programa e contratar os jovens, devendo matriculá-los devidamente nos cursos dos serviços nacionais de aprendizagem, salvo as Microempresas (ME), Empresas de Pequeno Porte (EPP), optantes pelo SIMPLES, e Empresas Sem Fins Lucrativos (ESFL), tendo uma cota mínima de $5 \%$ e máxima de $15 \%$ por estabelecimento. Os cargos de direção, trabalhos temporários e aprendizes já contratados não contam para o cálculo das cotas.

Os contratos têm prazo de dois anos e, durante esse período, o MTE fiscaliza as empresas e as instituições de ensino para acompanhar o desempenho dos jovens.

As instituições qualificadas para ministrar os cursos e devidamente enquadradas dentro do serviço nacional de aprendizagem são: Serviço Nacional de Aprendizagem Industrial (Senai), Serviço Nacional de Aprendizagem Comercial (Senac), Serviço Nacional de Aprendizagem Rural (Senar), Serviço Nacional de Aprendizagem do Transporte (Senat), Serviço Nacional de Aprendizagem do Cooperativismo (Sescoop), Escola Técnica de Educação e ESFL para assistência à educação profissional com registro no Conselho 
Municipal dos Direitos da Criança e do Adolescente (CMDCA), pois o menor recebe um certificado de qualificação ao término do curso.

Devem constar nos contratos firmados entre a instituição e a empresa: a qualificação da empresa; a qualificação do aprendiz; a identificação da entidade que ministra o curso; a designação da função; o salário; as jornadas diárias e semanais, com o tempo de prática e teoria. O tempo de trabalho e o de curso devem ser iguais, e a assinatura do aprendiz e do responsável legal pela empresa também devem constar.

É possível encontrar no site Conexão Aprendiz (2010) informações relevantes sobre a legislação do projeto, sobre o adolescente/jovem que pode participar, acerca de ONGs (organizações não governamentais), além de toda a parte burocrática que cabe às empresas, bem como informações relevantes sobre o trabalho infantil. $\mathrm{O}$ site disponibiliza, também, a Lei 11.180 de 23 de setembro de 2005, que altera a idade limite de aprendizes de 18 para 24 anos e institui o Projeto Escola de Fábrica, alterações fundamentais para que o programa possa se tornar cada vez mais eficaz. Os tópicos abaixo descrevem as principais informações relatadas no site.

Legislação

A Lei de Aprendizagem, número 10.097, promulgada em 19 de dezembreo de 2000, que altera a Consolidação das Leis do Trabalho - CLT (2001), determina que estabelecimentos de qualquer natureza devam ter de $5 \%$ a $15 \%$ de adolescentes (entre 14 e 24 anos incompletos) participantes de projetos de qualificação, tomando como base o quadro de funcionários cujas funções necessitem de formação profissional.

Pela alteração, a lei possibilita que a contratação e a formação dos adolescentes sejam feitas não só pelos Serviços Nacionais de Aprendizagem (Senai, Senat, Senac, Senar e Sescoop), mas também por Escolas Técnicas de Educação e por organizações sem fins lucrativos.

Adolescente/jovem

Os critérios necessários para que os jovens participem de projetos de qualificação profissional, em especial do projeto Jovem Aprendiz, abrangem jovens com idade entre quatorze a vinte e quatro anos incompletos, que estejam cursando ou concluindo o ensino fundamental e que tenham um vínculo com uma organização ou empresa que esteja participando de programa de aprendizagem.

Nesse programa de aprendizagem, o jovem pode ser contratado tanto pela empresa quanto pela organização de ensino, desde que fique assegurado o direito à formação profissional paralelamente ao ensino convencional.

É dever da empresa garantir o registro na carteira de trabalho e previdência social, bem como o pagamento do salário mínimo/hora como forma de remuneração ao aprendizado. 
Na forma de política de benefícios fiscais, a empresa que for parceira de projetos de qualificação profissional destinados a jovens terá a diminuição do FGTS de 8,5\% para $2,5 \%$, exceto para os contribuintes pelo simples, cuja redução é de $8,0 \%$ para $2,0 \%$.

Além disso, algumas condições são obrigatórias e devem ser rigorosamente seguidas pelo empregador no momento da contratação de jovens em fase de qualificação, como, por exemplo, o contrato de aprendizagem não poderá ser superior a dois anos.

Para o adolescente que estiver cursando o ensino fundamental, o contrato de aprendizagem é de seis horas diárias, nas quais devem estar computadas as horas de aprendizagem teórica. Nesse caso, o adolescente não pode fazer hora-extra nem trabalhar em locais insalubres. $O$ aluno de projetos de qualificação profissional poderá, ao completar 16 anos, ser efetivado, dependendo da atividade exercida na empresa.

Apesar de não ser obrigatório, micro e pequenas empresas também podem contratar aprendizes.

A Lei 11.180

O decreto-lei 5.598 de $1^{\circ}$ de dezembro de 2005, que regulamenta as contratações de jovens e permitem o trabalho de menores, como forma de aprendizado, é válido para a qualificação direta dos jovens.

Para tornar o decreto mais viável e abrangente, a lei 11.180 alterou a idade limite dos aprendizes de 18 para 24 anos e instituiu o Projeto Escola de Fábrica (CONEXÃO APRENDIZ, 2010). Nesse decreto-lei, podem ser encontradas diversas resoluções que especificam as normas a serem seguidas, tais como: a resolução $n^{\circ} 74$, que fiscaliza as entidades sem fins lucrativos; a instrução normativa $n^{\circ} 26$, que especifica as instruções para orientar a fiscalização das condições de trabalho no âmbito dos programas de aprendizagem; a nota técnica $\mathrm{n}^{\circ} 52$, que delimita o salário do aprendiz.

Diversas portarias ramificam a lei 11.180 tais como a portaria $n^{\circ} 984$, que institui o Fórum Nacional de Aprendizagem Profissional, com o objetivo de promover o debate sobre a contratação de aprendizes, a portaria $n^{\circ} 702$, que delimita as normas para avaliação da competência das entidades sem fins lucrativos, a portaria $n^{\circ} 4$, na qual podemos encontrar informações sobre os trabalhos que podem deixar de ser insalubres, se estiverem dentro de um padrão de segurança, e a portaria $n^{\circ} 20$, que trata dos trabalhos e lugares insalubres.

O decreto 5.598 regulamenta a contratação de aprendizes e dá outras providências. Já o decreto 2.208 de 17 de abril de 1997, delimita os objetivos da educação profissional.

Esse conjunto de normas legitima um processo de aprendizagem, dando segurança ao jovem e à empresa, pois quanto mais claras e específicas forem as normas, mais fácil de garantir o sucesso do processo. 
Trabalho infantil: legislação

No site do Ministério Público da União (2010), é possível encontrar dados úteis sobre a erradicação do trabalho infantil e sobre a regularização do trabalho do adolescente.

A proibição do trabalho para crianças e adolescentes com idade inferior a 16 anos, exceto na condição de aprendiz a partir dos 14 anos, está prevista nos artigos $7^{\circ}$, inciso XXXIII da Constituição Federal, 405, na CLT (2001), e 67, do Estatuto da Criança e do Adolescente (ECA). Os mesmos dispositivos vedam o trabalho noturno e as atividades insalubres e perigosas a adolescentes antes dos 18 anos, conforme melhor especificam a CLT e o ECA:

a) atividades insalubres (art. 405, inciso I, da CLT, e art. 67, inciso III do ECA), para Ihes preservar a boa saúde;

b) atividades perigosas (art. 405, inciso I, da CLT, e art. 67, inciso II do ECA), para Ihes preservar a vida;

c) atividades penosas (art. 405, § 5․ c/c com art. 390 da CLT, e art. 67, inciso II do ECA), para lhes preservar a integridade física;

d) trabalho noturno (arts. 404, da CLT, e art. 67, inciso I do ECA) e trabalhos que envolvam cargas pesadas, para lhes preservar o bom desenvolvimento físico (art. 405, parágrafo $5^{\circ} \mathrm{c} / \mathrm{c}$ art. 390 , da CLT);

e) jornadas de trabalho longas (arts. 403, § único, 411, 412 e 413 da CLT, e art. 67, inciso IV, do ECA), para lhes preservar o direito de frequentar a escola;

f) locais ou serviços que Ihes prejudiquem o bom desenvolvimento psíquico, moral e social (arts. 403, § único, e 405, inciso II e $\S 3^{\circ}$, da CLT, e art. 67, inciso II, do ECA).

Em relação à regularização do trabalho do adolescente, a coordenadoria do ECA foca sua atuação a partir dos institutos jurídicos da aprendizagem e do estágio.

Com efeito, o trabalho do adolescente, como aprendiz, está regulamentado na CLT (2001), artigos 428 e seguintes, com a redação dada pela Lei 10.097/2000 e Lei $11.180 / 2005$. Já o estágio é disciplinado pela Lei $11.788 / 08$, com base na qual o Ministério Público (MINISTÉRIO PÚBLICO, 2010) combate desvirtuamentos, para fins de utilização do estagiário como mão de obra barata, como verdadeiro empregado, sem qualquer garantia.

\section{Capital humano}

Historicamente, os trabalhadores, em geral, não eram vistos como valor dentro das organizações, e sim como parte da produção. Até mesmo o setor de recursos humanos era considerado dispensável. Porém, com a pluralidade dos mercados e com as evoluções industriais, o capital humano passou a ser reconhecido como intercambiável para o domínio do mercado.

Dada a importância do capital humano nas organizações, conceitua-se como sendo o conjunto de habilidades e conhecimentos dos indivíduos que, associado a outras 
características pessoais, aumentam as possibilidades de produção e de bem-estar pessoal, social e econômico (MARTELETO; OLIVEIRA E SILVA, 2004).

Assim, em uma sociedade liberal e cada vez mais globalizada, as competências regem os líderes nas respostas e os guiam para grandes transformações, em um mercado absolutamente mutável. Ponchirolli (2002) afirma que os investimentos para desenvolver os recursos essenciais não podem ser considerados despesas, pois serão necessários para assegurar vantagens a médio e longo prazo, e que o aprendizado - no âmbito de fazer, conhecer e saber conviver - será primordial no mercado competitivo.

De outra forma, o papel do capital humano nas organizações, que é composto por um conjunto de fatores de natureza cultural, que aumenta a propensão dos atores sociais para a colaboração e para empreender ações coletivas, constitui-se em importante fator explicativo das diferenças regionais quanto ao nível de desenvolvimento (BANDEIRA, 1999).

De igual importância torna-se o exercício ético dentro das organizações, pois, no mundo globalizado, onde diversas culturas se encontram em uma mesma empresa, facilmente os gestores se utilizam do simples uso do poder na manipulação das ações. A ética, dentro de uma organização, deixa de ser uma simples cartilha de normas para se tornar o elemento que trará entendimento sobre a cultura e o modo de pensar e agir de cada colaborador.

Pode parecer discordante, mas o capital humano foi realmente valorizado no capitalismo, uma vez que foi visto como uma alavanca para o crescimento e a riqueza em uma economia livre, ao contrário do socialismo, cuja economia controlada não permitia um maior diferencial entre as organizações (FRIEDMAN; HATCH; WALKER, 2000).

$O$ agir com ética nas empresas faz com que o capital humano tenha realmente valor, pois coloca o colaborador como peça indispensável para o desenvolvimento dos projetos, o que, consequentemente, significa crescimento para ambas as partes. Já a inteligência individual não pode ser contabilizada como um ativo dentro da organização, pois, se o colaborador se desligar da instituição, automaticamente, levará consigo todo seu conhecimento.

Stewart (1998) cita a grande importância da informação dentro das organizações, pois todos os setores compartilham de forma maciça o seu uso, utilizando o conhecimento como fonte de atrair clientes e consumidores, e a tecnologia da informação, para uso gerencial.

Pode-se dizer que a probabilidade de eficácia é altamente agregada ao capital humano das empresas, tornando-as mais competitivas perante as concorrentes, o que requer uma atualização constante dos conhecimentos e aprimoramento cultural de todos os cargos das empresas, principalmente dos gestores e dos cargos com poderes de decisão. Esse saber deve ser incorporado à organização, fazendo dele um instrumento para sistemas de execução, padronização de ações, caráter de relacionamento com os clientes e eficácia na solução dos problemas.

Nogueira et al. (2008, p. 144) conceituam a gestão de capital humano da seguinte forma: 
A gestão do Capital Humano envolve os custos incorridos por entidades para recrutar, selecionar, contratar, treinar e desenvolver ativos humanos. Incorpora, também, em decorrência da contratação, do treinamento, da formação e da conservação dos recursos humanos, o reconhecimento do valor que esses recursos proporcionam às entidades - e que precisam ser devidamente contabilizados, mensurados, analisados, avaliados e divulgados.

Planejamento com eficácia e um sistema de gestão integrado podem resultar em retorno mensurável para a empresa, pois ela deve saber que um grupo de indivíduos, assim como os ativos físicos, possui capacidade de gerar lucros e serviços que agregam às organizações.

\section{Responsabilidade social}

O Instituto Ethos de Empresas e Responsabilidade Social (2010), responsável por diversas publicações do gênero, define responsabilidade social quando as organizações estabelecem metas compatíveis com o desenvolvimento sustentável, embasando as formas de gestão na ética e na transparência das empresas, sem deixar esquecidos os recursos ambientais e culturais para as futuras gerações, ressaltando a diminuição da desigualdade social e respeitando a diversidade.

Chiavenatto (2008, p. 483) conceitua responsabilidade social da seguinte maneira:

Responsabilidade social significa a atuação responsável socialmente de seus membros, as atividades de beneficência e os compromissos da organização com a sociedade, em geral, e de forma mais intensa com aqueles grupos ou partes da sociedade com a qual está mais em contato. A responsabilidade social está voltada para a atitude e comportamento da organização, em face das exigências sociais da sociedade, em consequência das suas atividades.

Vários são os fatores que podem ser citados como ações de responsabilidade social e suas consequências. A principal delas atinge diretamente a imagem da empresa perante seus fornecedores, clientes, colaboradores e sociedade em que está inserida.

Félix (2002, p. 6) menciona várias iniciativas de responsabilidade social dentro das empresas:

Essas seriam, além do devido cumprimento dos direitos trabalhistas, também o propicio de um aprendizado permanente; uma melhora do nível de informação sobre a empresa; um maior e melhor equilíbrio entre trabalho, família e lazer; uma maior diversidade de recursos humanos; uma maior igualdade salarial; perspectivas profissionais para as mulheres; participação dos lucros para os empregados; participação do empregado em algumas decisões da empresa; respeito e aproveitamento adequado da formação dos trabalhadores; e a não descriminação de trabalhadores do sexo feminino ou de indivíduos advindos de minorias étnicas.

A responsabilidade social pode ser vista nas ações éticas, morais, culturais das organizações, principalmente no poder de decisão dos gestores, quando tomam uma postura seguindo princípios, não apenas como jogada de marketing, mas como forma 
de reconhecer que são diretamente responsáveis pelo ambiente em que habitam. Sendo assim, a sociedade vê a empresa como responsável por seus atos, pois elas representam parte das mudanças sociais, segundo Nogueira et al. (2008).

Em seu artigo, Felix (2002) diz que o número de organizações que adotam critérios da responsabilidade social perante a contratação de funcionários ainda é reduzido, tanto que poucos projetos como o Jovem Aprendiz e programas de contratação de portadores de necessidades especiais e de cotas para afro-descendentes, entre outros, são utilizados de forma tímida.

Para Perazzo (2010, p. 4):

Empresa solidária é o nome que pode perfeitamente identificar uma organização que tenha uma visão ética e socialmente responsável. Uma empresa que seja verdadeiramente transformadora, não pela sua inércia, mas pela atitude de seus talentos.

Conforme Breternitiz e Almeida (2002), as empresas já utilizam auditores externos para verificarem a eficácia de suas políticas e o alcance de metas na área da responsabilidade social, da mesma maneira como coletam informações para revisão de contas, procedimentos contábeis e áreas tecnológicas. Isso demonstra que, cada vez mais, a responsabilidade social fará parte da cultura das organizações.

A partir dos relatos acima, pode-se dizer que os autores compartilham da convicção de que a responsabilidade social não se trata de filantropia, pois todas as empresas existem e sobrevivem de lucros. O que se foca, neste caso, são as ações e as formas como são executadas, o investimento na cultura e na educação, a inclusão social e o meio ambiente, o que acaba fidelizando clientes, fornecedores, investidores e empregados, melhorando a imagem da empresa, aumentando o volume de vendas e baixando os custos operacionais.

\section{Empresa cidadã}

Alves (2001) conceitua uma empresa cidadã como sendo um todo, ou seja, um conjunto de princípios e uma sistemática de gestão para assegurar a criação ou a preservação de valores sociais. Esse conceito leva-nos à conclusão de que a organização precisa adotar atitudes éticas desde a gerência até a produção. O conceito de cidadania deve ser introduzido na imagem que a empresa passa para seus clientes internos, externos, fornecedores e à sociedade em que está inserida.

Para Félix (2002), inicialmente, o desenvolvimento da imagem de empresa cidadã tornou-se importante a partir do neoliberalismo, pois a postura de várias empresas modificou-se desde que o Estado deixou de tomar a posição de fornecedor e realizador de políticas sociais. Assim, as organizações se sentiram, em parte, responsáveis pela situação de exclusão e injustiça social.

Alves (2001) afirma que a empresa que se compromete com outros objetivos, e não apenas com a geração de riqueza material, denominada por ele de empresa social, ganhou força entre os anos 1960 e 1970, "[...] promovida por correntes de pensamento e movimentos de protesto que propunham modelos críticos e alternativos ao capitalis- 
mo avançado e à sua instituição fundamental: a empresa" (p. 80).

Facilmente se relacionam atitudes de uma empresa cidadã à imagem de uma organização que atua conforme uma conduta de responsabilidade social. Ambas se confundem, pois, para uma empresa abranger todo o contexto de responsabilidade social, deve, tão logo, tornar-se uma empresa cidadã, tomando uma postura ética perante qualquer situação.

Dessa forma, a consciência social é muito individual. O "agir socialmente" torna-se hábito rotineiro e grandes avanços podem ser observados dentro das organizações, com metas específicas, parcerias com organizações sociais, e até mesmo dentro do próprio $\mathrm{RH}$, que pode direcionar, por exemplo, programas como o Jovem Aprendiz.

Félix (2002, p. 5) menciona a importância da organização socialmente cidadã:

Assim, ser socialmente responsável não significa respeitar e cumprir devidamente as obrigações legais, mas sim, o fato das empresas, através dos trabaIhadores e de todos seus interlocutores, irem além de suas obrigações em relação ao seu capital humano, ao meio ambiente e a comunidade, por perceber que o bem-estar destes reflete em seu bem-estar.

Portanto, o ambiente que se cria dentro de uma organização que age conforme critérios específicos de empresa-cidadã, não renuncia a busca pelo lucro - fim maior de qualquer empresa privada -, porém o conceito de lucratividade deixa de ser apenas material e passa a abranger valores intangíveis, como a valorização do ser humano, o desenvolvimento sustentável e a dignidade do trabalho.

\section{Ética empresarial}

Em um conceito simplificado, pode-se dizer que "ética empresarial é o comportamento da empresa - entidade lucrativa - quando ela age de conformidade com os princípios morais e as regras do bem proceder aceitas pela coletividade" (MOREIRA, 2002, p. 28). Essa definição conota três aspectos fundamentais da ética empresarial, que são: a empresa, o lucro como objetivo principal e as pessoas, quando se refere à coletividade.

É indispensável salientar que, indiferente de ser de pequeno ou grande porte, familiar ou multinacional, capital aberto ou fechado, as empresas são formadas por pessoas e por suas ações. Bernardes e Marcondes (2003, p. 57) afirmam que "[...] primeiramente, as organizações são grupos humanos que se autoperpetuam ao mesmo tempo em que seus participantes levam a efeito grande parte de suas interações dentro das organizações."

Moreira (2002) defende que, mesmo nos tempos atuais, em que o lucro é perseguido a qualquer custo, a ética está cada vez mais valorizada pela sociedade. "Os procedimentos éticos facilitam e solidificam os laços de parceria empresarial, quer com clientes, quer com fornecedores [...]. Isso ocorre em função do respeito que um agente ético gera em seus parceiros" (MOREIRA, 2002, p. 31). Portanto, a honestidade e o respeito norteiam as relações comerciais, uma vez que esse princípio vale tanto para as empresas em relação aos seus stakeholders, quanto para estes com relação às empresas.

A ética parte de cada indivíduo. Cada funcionário é responsável pelos seus atos e 
deve agir de forma ética, porém as atitudes da administração da empresa serão sempre determinantes. "O exemplo demonstrado pelos dirigentes da organização cala mais fundo nos funcionários de uma organização do que qualquer declaração de seu presidente, por mais acertadas que sejam suas palavras e seus conselhos" (ARRUDA, 2002, p. 3).

Partindo do princípio exposto por Arruda (2002), a área administrativa deve exemplificar a ética. Seriam necessárias, então, a criação e/ou a adoção de um código de ética?

Há autores que afirmam essa possibilidade, pois, por meio do código de ética, é possível identificar os valores e comportamentos considerados ideais dentro de cada empresa, já que as normas são exclusivas de cada organização, sem nenhum tipo de imposição legal.

A postura ética da organização é formada pela soma, numa construção cotidiana de valores e interações. Sabe-se que a ética está plantada dentro de cada indivíduo e forma o conjunto da organização. Essas atitudes individuais formam o espelho da empresa. Além disso, agindo de forma honesta e transparente, automaticamente, reflete a imagem da organização perante a sociedade.

\section{Políticas públicas}

Embora as políticas públicas destinadas aos jovens no Brasil tenham sido pouco estudadas, é possível perceber algumas evoluções.

Sposito e Carrano (2003) afirmam que as ações de políticas públicas tratam do universo geral dos jovens e do mundo adulto, tendo como elemento o poder exercido pelas instituições, nas quais o jovem encontra possibilidades de interação, conflito, destaque e solidariedade.

Historicamente, tem-se conhecimento de que, nos anos 1960, os jovens eram vistos como pivô dos problemas sociais devido aos conflitos de gerações, situados sobre paradigmas éticos e culturais. A partir de 1970, o emprego e o início da vida ativa dos jovens tornaram essenciais os estudos sobre a juventude (SPOSITO; CARRANO, 2003).

Lagree apud SPOSITO e CARRANO (2003, p. 19), também cita a importância de como a juventude deve ser vista aos olhos do poder público e da sociedade:

Os jovens ora são vistos como problemas ou como setores que precisam ser objeto de atenção. Manter a paz social ou preservar a juventude? Controlar a ameaça que os segmentos juvenis oferecem ou considerá-los como seres em formação ameaçados pela sociedade e seus problemas?

A criação de projetos públicos de educação e de qualificação profissional para jovens é uma forma de transformar uma situação problema em benefícios sociais individuais e coletivos.

França Filho et al. (2006) expõem que, na tentativa de expansão das políticas municipais para o âmbito estadual, seguiram-se duas linhas gerais de raciocínio: a atuação regionalizada e a parceria com entidades da sociedade civil. Assim, a economia solidária teve estratégias de desenvolvimento e metas específicas.

Ao citar sobre a eficácia das políticas, Noronha (2003, p. 15-16) destaca uma nova 
fase no que diz respeito a programas de inclusão:

A legislação e as entidades estão prontas, e o principio da inclusão social é um só. Agora, só depende de nós a articulação com a sociedade, a sensibilização das pessoas e a criação de uma cultura de Aprendizagem, cujos princípios filosóficos estejam afinados com a dinâmica, pois, do contrário, não há eficácia. O que importa não é a quantidade de menores inscritos no programa, mas a qualidade do trabalho desenvolvido com eles.

A Constituição Federal, por meio do Artigo 227, prevê a profissionalização como um dos direitos prioritários da infância e da adolescência, porém veda o trabalho ao menor de dezesseis anos, salvo na condição de aprendiz (MINISTÉRIO PÚBLICO DA UNIÃO, 2010).

A lei da aprendizagem delega que o Estado, a família e a sociedade, a partir de leis orçamentárias, previsão e execução de políticas públicas, garantam o declive do triste quadro social de crianças excluídas por falta de assistência e de condições mínimas de qualificação.

Fica claro que é necessária a construção de espaços de políticas publicas, onde a união do Estado com a sociedade civil aproxima o poder às necessidades da população. $\mathrm{O}$ assistencialismo torna-se ineficiente e não resolve o cerne dos problemas sociais. É preciso programas com metas e recursos específicos, dando à sociedade o poder de discutir novos caminhos.

\section{Descrição e análise dos dados}

Sendo o tema principal desta pesquisa a inclusão do Jovem Aprendiz e as suas diferentes visões, foi elaborada uma entrevista prévia, cujas perguntas visavam conseguir o máximo de informações importantes que vislumbrassem as visões distintas dos entrevistados sobre a inclusão dos jovens, a pré-disposição para a responsabilidade social e o comprometimento com programas de inclusão.

A partir da lei de inclusão, que coloca o jovem diretamente relacionado ao mercado de trabalho e à sociedade em que está inserido, julgou-se necessário buscar depoimentos do MTE, do Senai e de uma indústria calçadista, situada no município de Igrejinha/RS. Esse município pertence ao Vale do Paranhana, conhecido por abrigar várias indústrias calçadistas, sendo esse o principal potencial da região.

Por meio da pesquisa, foi possível observar alguns pontos importantes levantados pelos entrevistados. O primeiro se refere à aprendizagem e à qualificação profissional.

Pode-se perceber que a aprendizagem do jovem é igualmente importante na visão do MTE, pois não há como diferenciar atividades que demandam ou não formação qualificada. Toda a atividade é digna e demanda formação.

A organização que consegue ampliar o ambiente em que atua, deixando de olhar a qualificação apenas como treinamento, mas como um benefício para a sociedade, conforme Torres (2003), passa a considerar a aprendizagem um ramo infinito de atividades.

Confirmando esse pensamento, a entrevistada representante do MTE relata que a qualificação, a partir da lei Jovem Aprendiz, é uma obrigação legal, que conduz o jovem 
a um caminho seguro, beneficia o empresário com mão de obra qualificada, bem como a comunidade.

É possível observar que nem todas as empresas estão preparadas para gerenciar a qualificação, pois muitos empresários não veem o aprendizado como rendimentos de ativo.

Por meio de relatos do diretor do Senai do município de Igrejinha/RS, pode-se constatar que, para algumas empresas, o aprendiz ainda significa um custo. Esse tipo de empresa contrata o jovem apenas para cumprir a lei.

Por outro lado, o entrevistado considera um exagero as normas propostas pelo Ministério do Trabalho referentes à Classificação Brasileira de Ocupações (CBO), em que todas as ocupações demandam formação profissional.

Com essa afirmação, o entrevistado deixa claro que tarefas simples, como as de auxiliar de produção, que não demandam formação profissional, não necessitariam onerar as empresas com tamanha despesa, deixando esse investimento apenas para cargos que realmente exijam tal qualificação. Ao analisar em âmbito geral a indústria calçadista, um número expressivo de empregados cairia fora do cálculo para cotas de aprendizes.

Várias qualidades são despertadas no jovem quando ele se sente inserido em um processo de qualificação. Noronha (2003) cita entre elas a disciplina, a organização, a ética, a responsabilidade e a autoestima.

O entrevistado, representante do Senai, torna relevante um dado, pois, quando coloca aos jovens que a qualificação não é a garantia de um bom emprego e de renda, desperta o senso da humildade e da responsabilidade.

O entrevistado, representando a indústria calçadista, afirma que a qualificação muitas vezes não está enraizada na visão de crescimento dos jovens. Atualmente, os jovens se interessam por informática ou administração, ingressando no programa apenas buscando uma renda e não preparando uma profissão. Mesmo encontrando dificuldades, a empresa busca soluções práticas para resolver tais impasses. Uma delas seria a criação de um centro de treinamento, uma escola de fábrica para os jovens, em parceria com o Senai.

Conforme os entrevistados, a união de esforços entre as partes envolvidas - órgãos públicos, empresas privadas e sociedade em geral - supriria várias necessidades, dentre elas a qualificação de mão de obra e a inclusão social.

Outro item a ser tratado é a questão da idade, uma barreira imposta pela lei. Conforme a Constituição Federal, a CLT e o Estatuto da Criança e do Adolescente, é de conhecimento geral que o adolescente, com idade inferior a dezoito anos, pode trabalhar como aprendiz, salvo alguns empecilhos, tais como jornada longa, atividades penosas, perigosas, trabalho noturno e em locais que sejam considerados insalubres.

Assim, o entrevistado da indústria calçadista reforça o fato da barreira que a idade proporciona para a efetiva atuação do projeto de qualificação. Quando a empresa contrata um jovem de quatorze anos, o risco é a questão do trabalho infantil. Um jovem de quatorze anos ainda é considerado criança pela Organização Internacional do TrabaIho (OIT).

Da mesma forma, o Senai admite que a barreira de idade é um complicador nos dias atuais e não condiz com a realidade que o país enfrenta, pois com dezesseis anos o 
adolescente pode votar, fumar, traficar, namorar, mas não pode trabalhar em uma empresa na condição de aprendiz, monitorado e supervisionado pelo Senai ou por alguém da própria empresa.

As limitações impostas pela lei, por meio do Estatuto da Criança e do Adolescente, vêm assegurar os direitos dos menores a fim de coibir o abuso e a exploração da mão de obra infantil. Mas, dada a necessidade de educação e de qualificação profissional e até mesmo de retirar muitos adolescentes das ruas, dando a opção de, no futuro, terem uma profissão, surge a pergunta: a legislação atual está ou não de acordo com a realidade vivenciada pela sociedade e pelas indústrias?

No segmento calçadista, fica claro, pela visão do entrevistado, que muitos jovens se engajam no processo de qualificação apenas como busca de complementação de renda, sem dar a devida importância ao aprendizado.

Para o representante do Senai, a opinião é idêntica. O jovem adere ao programa de aprendizagem muitas vezes apenas para ajudar na renda familiar.

O entrevistado (Senai) destaca o lado positivo da qualificação para os menores, afirmando que as empresas não teriam resistência em admitir jovens a partir dos dezesseis anos na condição de aprendiz. Na visão do Senai, a possibilidade do jovem estar como aprendiz em uma empresa em turno contrário ao da escola evitaria alguns problemas como, por exemplo, o consumo de drogas.

Todas as partes envolvidas nessa entrevista citam, de forma clara, que a qualificação, de modo correto, traria inúmeros benefícios à sociedade. Os maiores beneficiários seriam os jovens, pois garantiriam a qualificação e a vivência com o ambiente de trabaIho. Caberia, então, um ajuste entre a legislação e a necessidade atual.

Quando a lei do Jovem Aprendiz é implantada de maneira correta, vê-se a qualificação refletida na sociedade em que o jovem está inserido, pois, a partir do convívio com outras pessoas dentro do ambiente escolar ou do trabalho, o aluno acaba assimilando as várias informações recebidas, melhorando sua condição social, principalmente no âmbito da educação e da qualificação profissional para o mercado de trabalho.

A indústria cobra mais empenho do Senai a fim de receber o retorno do investimento ( $1 \%$ da folha de pagamento da indústria é destinada ao Senai), oferecendo cursos de qualidade e formando jovens preparados para o mercado de trabalho.

Dentro do Senai, os alunos recebem, além do treinamento técnico, aulas de convivência, o que inclui boas maneiras e limites dentro do ambiente de trabalho. Para o Senai, é importante que o aluno saia consciente de que esse foi apenas o primeiro passo da sua formação profissional.

Por sua vez, o Ministério do Trabalho destaca que o programa de aprendizagem dá outra visão de mundo para os jovens, que, mesmo se deslocando de cidades menores para grandes centros, estarão fora das filas de desempregados e inseridos no mercado de trabalho.

A valorização da qualificação deve passar por todos os envolvidos, jovem, indústria e educador. De um modo geral, todos devem estar engajados em busca de um resultado promissor. É verídico que a qualificação abre portas, mas não assegura empregos. Somente com muita dedicação e reconhecimento é possível chegar ao sucesso profissional. 
A empresa, por determinação legal, fica responsável pela contratação e pelo encaminhamento à instituição de ensino que fará a qualificação teórica do aprendiz.

O grande impasse dessa questão é a parte motivacional do jovem, pois, conforme relato do entrevistado do Senai, as empresas encontram dificuldades para o recrutamento e contratação. Um dos motivos é a empresa ser inexperiente em identificar e contratar jovens aprendizes. Além disso, em alguns locais, há escassez de candidatos.

Observou-se que uma das motivações no processo de aprendizagem é o fato de o jovem receber um salário que, no programa Jovem Aprendiz, é compatível a meio período de trabalho, com carteira assinada e assegurados os direitos sociais. Porém, o recebimento mensal fica abaixo do valor pago no mercado informal, levando o jovem a abandonar a qualificação caso consiga outro emprego como funcionário e ganhando salário integral.

Ambos os entrevistados acreditam que o recrutamento não deveria ser responsabilidade da empresa, bem como a motivação para que o jovem conclua todo o processo de qualificação. Essas fases devem ser reestruturadas e muito trabalhadas pelos orientadores, englobando todos os setores envolvidos nesse projeto.

O Sistema " $S$ " foi criado para esse suporte: a qualificação dos segmentos profissionais. Esse sistema é gerido pelas empresas que, desde o governo de Getúlio Vargas, têm $1 \%$ do total de recolhimentos da sua folha de pagamentos, destinados ao seu " $\mathrm{S}$ " correspondente. Porém, conforme a entrevistada do Ministério do Trabalho, a grande maioria dos empresários desconhece essa informação.

Ações de políticas públicas direcionadas aos jovens, como forma de qualificação, servem de base para a fase adulta, onde o indivíduo consegue, por meio do seu trabalho e de suas competências, a realização profissional.

Não somente o indivíduo passa a ter um melhor conhecimento técnico da sua área de atuação, mas, se a cultura da aprendizagem se expandir e atrair cada vez mais integrantes, toda a sociedade sentirá as lucrativas consequências.

\section{Considerações finais}

Este trabalho teve como objetivo compreender como a empresa pesquisada utiliza o projeto Jovem Aprendiz, e se sua implantação serve apenas para cumprir a legislação vigente ou se a mesma está realmente preocupada com a inclusão e com a responsabilidade social.

Foi necessária a utilização de entrevistas com os três setores igualmente importantes na aplicação de projetos como o Jovem Aprendiz, sendo eles o MTE, Indústria e Senai.

A abordagem dos diferentes temas em estudo mostrou ser a responsabilidade social o norte para qualquer organização. Além disso, os segmentos responsáveis, como MTE, indústria e Senai, devem trabalhar juntos com um único propósito, que é a qualificação e formação dos jovens, para que aprendam conceitos éticos de trabalho e dignidade.

A partir dos dados coletados e descritos, fica evidente que todos os setores en- 
trevistados têm relevante preocupação com o aprendizado, especificamente dos jovens, assunto desta pesquisa, empenhando-se para cumprir a legislação e sanar a lacuna que existe entre juventude, qualificação e emprego. Apesar de terem o mesmo foco, apresentam opiniões divergentes sobre a implantação do projeto.

O MTE expressa que, a partir da qualificação, o jovem consegue se identificar com o trabalho, assim esse tipo de projeto abrange um cinturão da sociedade, possibilitando a qualificação para todos, inclusive aos que não dispõem de recursos financeiros.

Por outro lado, o representante de indústria calçadista cita que, apesar do projeto ser abrangente, ele não consegue atingir a totalidade de jovens, pois faltam vagas para qualificação, ou seja, as escolas que deveriam formar esses jovens não conseguem absorver a grande demanda, deixando lacunas de vagas disponíveis dentro das empresas.

Dentro do setor industrial, é evidente a necessidade de profissionais qualificados, destacando-se a importância do jovem participar não só das aulas teóricas, como do ambiente e da prática profissional na empresa, pois a prática é que diferencia esse projeto do assistencialismo. A qualificação não é a garantia de uma rápida colocação dentro do mercado de trabalho, tampouco a segurança de logo atingir cargos de liderança, porém o que é passado para esses jovens é que somente por meio desse crescimento é possível alcançar alguns objetivos. É o processo de qualificação que os deixa mais competitivos no mercado de trabalho e aptos para a execução das suas funções.

Conforme o Ministério do Trabalho, não há uma fiscalização efetiva dentro das empresas, pois muitas instituições de ensino ainda não comportam as vagas necessárias para a qualificação dos jovens, porém, ele ressalta que as empresas devem cobrar essas vagas diretamente do seu "sistema $S$ " correspondente, pois cada empresa contribui diretamente para a manutenção do seu sistema (Senai, no caso entrevistado) com $1 \%$ da sua folha de pagamento.

Atualmente, a empresa é responsável pelo jovem desde o seu ingresso na escola de qualificação. Consequentemente, toma para si a divulgação do projeto e o recrutamento dos jovens. Esse trabalho é feito por meio de cartazes dentro das organizações, ou de maneira informal, avisando aos funcionários que indiquem filhos ou conhecidos que estejam estudando e que tenham idade compatível com a proposta do projeto para o encaminhamento ao Senai.

Os participantes da pesquisa deixam clara a importância desse trabalho, porém ele deve ser aperfeiçoado, aumentando a sua abrangência e propondo um trabalho conjunto entre governos, instituições de ensino e sociedade.

O Senai/Igrejinha não divulgou dados quantitativos dos jovens que participaram dos processos de qualificação Jovem Aprendiz e que permanecem empregados nas empresas, tampouco o cargo que ocupam, porém já existem pesquisas sendo aplicadas para que esses dados sejam computados e divulgados.

Outro fator que impede o crescimento do projeto Jovem Aprendiz diz respeito à idade mínima para ingresso dos jovens nas empresas, pois a legislação brasileira não permite que menores atuem em atividades insalubres, mesmo na forma de aprendizes.

A participação efetiva da empresa, das instituições de ensino e do governo tende a refletir diretamente na sociedade, formando jovens mais qualificados e inserindo, na vida desses jovens, a importância da busca pelo aprendizado, o qual tende a resultar em 
melhores condições de trabalho e renda.

Há um longo caminho a ser percorrido para que possamos construir uma sociedade modelo, com ideais sociais, atitudes éticas e comprometimento com o bem-estar dos jovens. Porém, o primeiro passo já foi dado, quando da criação da legislação que regulamenta o processo de inclusão dos jovens no mercado de trabalho. Agora, necessitam-se coerência e empenho das entidades responsáveis e das empresas para que o projeto Jovem Aprendiz consiga despertar nos jovens o interesse pelo desenvolvimento pessoal, disseminando, assim, na sociedade, uma cultura baseada no trabalho com dignidade e comprometimento com o futuro.

Por fim, o papel desempenhado pela participação dos setores público, privado, sociedade civil, comunidade no processo de formação e consolidação das identidades regionais, buscando, por meio de projetos como o Jovem Aprendiz, incentivar a formação intelectual e profissional da sociedade, representam os pilares da construção de um consenso comum voltado para a promoção do desenvolvimento regional.

\section{Referências}

ALVES, Lauro Eduardo Soutello. Governança e cidadania empresarial. RAE - Revista de Administração de Empresas, São Paulo, v. 41, n. 4, out./dez. 2001.

ARRUDA, Márcia Cecília Coutinho de. Código de ética: um instrumento de valor. São Paulo: Negócio, 2002.

BANDEIRA, Pedro. Participação, articulação de atores sociais e desenvolvimento regional. Texto para discussão $n^{\circ} 630,1999$. Disponível em: <www.ipea.gov.br>. Acesso em: 20 jul. 2010.

BERNARDES, Cyro; MARCONDES, Reynaldo. Teoria Geral da Administração - gerenciando organizações. São Paulo: Saraiva, 2003.

BRETERNITZ, Vivaldo José; ALMEIDA, Sérgio Roberto Porto de. Administração e Responsabilidade Social. Revista da Faculdade de Ciências Econômicas, Contábeis e de Administração de Empresas Padre Anchieta, Jundiaí, 2002.

CHIAVENATTO, Idalberto. Recursos humanos: o capital humano das organizações. 8. ed. São Paulo: Atlas, 2008.

CONEXÃO APRENDIZ. Um projeto a partir de uma lei. Disponível em: <http://www.conexaoaprendiz.org.br>. Acesso em: 4 jul. 2010.

CONSOLIDAÇÃO DAS LEIS DO TRABALHO. 28. ed. São Paulo: Saraiva, 2001.

FÉLIX, Luiz Fernando Fortes. O ciclo virtuoso do desenvolvimento responsável. Disponível em: <http://www.ethos.org.br/_Uniethos/Documents/O\%20Ciclo\%20 Virtuoso\%20do\%20Desenvolvimento\%20Respons\%C3\%A1vel.pdf>. 2002. Acesso em: 28 jun. 2010.

FRANÇA FILHO, Genauto Carvalho et al. (Orgs.). Ação pública e economia solidária: uma perspectiva internacional. Porto Alegre: UFRGS, 2006. 
FRIEDMANN, Brian; HATCH, James; WALKER, David M. Como atrair, gerenciar e reter capital humano: da promessa à realidade. 2. ed. São Paulo: Futura, 2000.

INSTITUTO ETHOS DE EMPRESAS E RESPONSABILIDADE SOCIAL. Disponível em: $<$ http://www1.ethos.org.br/EthosWeb/pt/93/servicos_do_portal/perguntas_frequentes/ perguntas_frequentes.aspx>. Acesso em: 25 abr. 2010

MARTELETO, Regina Maria; OLIVEIRA E SILVA, Antonio Braz. Redes e Capital Social: o enfoque da informação para o desenvolvimento local. Brasília. Disponível em: <www.scielo.br/pdf/ci/v33n3/a06v33n3.pdf>. Brasília, v. 33, n. 3, p. 41-49 set./dez. 2004.

MINISTÉRIO PÚBLICO DA UNIÃO. MPU. Trabalho Infantil - Legislação. Disponível em: <http://www.pgt.mpt.gov.br/atuacao/trabalho-infantil/trabalho-infantil-legislacao. html>. Acesso em: 22 jul. 2010.

MOREIRA, Joaquim Magalhães. A Ética Empresarial no Brasil. São Paulo: Pioneira, 2002.

NOGUEIRA M. A. et al. Gestão Social, estratégias e parcerias: Redescobrindo a essência da administração brasileira de comunidades para o Terceiro Setor. São Paulo: Saraiva, 2008.

NORONHA, Solange. O Futuro começa aqui. Rio de Janeiro: Senac Nacional, 2003.

PERAZZO, Alberto Augusto. Uma visão empresarial ética e socialmente responsável. Disponível em: <http://www.fides.org.br/artigos.htm>. Acesso em: 21 mar. 2010.

PONCHIROLLI, Osmar. O capital humano como elemento estratégico na economia da sociedade do conhecimento sob a perspectiva da teoria do agir comunicativo. Revista FAE, Curitiba, v. 5, n. 1, p. 29-42, jan./abr., 2002.

SILVA, Luiz Inácio Lula da et al. Manual da Aprendizagem: O que é preciso saber para contratar o aprendiz. 4. ed. rev. amp. Brasília, 2009.

SPOSITO, Marília Pontes; CARRANO, Paulo César Rodrigues. Juventude e Políticas Públicas no Brasil. Revista Brasileira de Educação, Rio de Janeiro, n. 24, 2003.

STEWART, Thomas A. Capital intelectual: a nova vantagem competitiva das empresas. 3. ed. Rio de Janeiro: Campus, 1998.

TORRES, Julia Maria Pereira. O Valor Humano da Empresa: Valorização das Pessoas como Ativos. São Paulo: Pearson, 2003. 